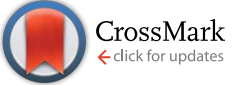

Cite this: RSC Adv., 2015, 5, 23009
Received 26th January 2015

Accepted 24th February 2015

DOI: $10.1039 / \mathrm{c} 5 \mathrm{ra01515d}$

www.rsc.org/advances

\title{
Propargyl ether-functionalized poly( $m$-phenylene): a new precursor for the preparation of polymers with high modulus and high $T_{\mathrm{g}}^{\dagger}$
}

\begin{abstract}
Yijie Luo, ${ }^{a}$ Jing Sun, ${ }^{\star a}$ Kaikai Jin, ${ }^{a}$ Jiajia Wang, ${ }^{a}$ Guangsu Huang ${ }^{b}$ and Qiang Fang ${ }^{\star a}$
A propargyl ether-functionalized poly( $m$-phenylene) (PE-PMP) is reported here. This polymer exhibits good solubility and film-forming ability. After postpolymerization at high temperature, the polymer transforms to a cross-linked network, which shows high thermostability with a $5 \%$ weight loss temperature at $471^{\circ} \mathrm{C}$ and a char yield of $67 \%$ at $1000{ }^{\circ} \mathrm{C}$ under $\mathrm{N}_{2}$. Thermo-mechanical analysis (TMA) reveals that the cured polymer shows an average linear coefficient of thermal expansion (CTE) of $30.6 \mathrm{ppm}{ }^{\circ} \mathrm{C}^{-1}$ ranging from 30 to $300^{\circ} \mathrm{C}$ and a glass transition temperature $\left(T_{\mathrm{g}}\right)$ near $330^{\circ} \mathrm{C}$. Moreover, even at temperatures up to $300^{\circ} \mathrm{C}$, the cured polymer possesses a storage modulus exceeding 4.0 GPa. These data are superior to those of the commercial epoxy and novolac resins and polyimides. Furthermore, the cured polymer film has good mechanical properties with hardness, Young's modulus and a bonding strength to a silicon wafer of 1.22 , 9.44 and $0.78 \mathrm{GPa}$, respectively. The cured polymer film also shows good dielectric properties with an average dielectric constant of 2.93 in a range of frequencies from $2 \mathrm{MHz}$ to $30 \mathrm{MHz}$. Such results suggest that the polymer is a useful precursor for preparation of insulating materials with high modulus and $T_{\mathrm{g}}$ in the microelectronics industry.
\end{abstract}

\section{Introduction}

Much attention has been paid to polymers consisting of paralinked phenylene (PPPs) units in their main chains in the past decades due to their excellent optical and electronic properties..$^{1-12}$ These polymers usually are electrochemically active, and show light emitting properties. Therefore, they have been successfully developed and widely used as the optoelectronic materials in industry.

In comparison with PPPs, the polymers consisting of metalinked phenylene units in their main chains (PMPs) have gathered an increasing interesting in the recent years. ${ }^{13-21}$ Quantum-chemical study reveals that PMPs prefer helical conformations with a helical angle of $72^{\circ}$ between two benzene rings in the solid state, ${ }^{22}$ which endow the polymers with unique properties such as good solubility and toughness benefiting from the flexible chains. In particular, the introduction of some special side chains into the backbone of PMPs makes the polymers have interesting properties including helical folding

${ }^{a}$ Key Laboratory of Synthetic and Self-Assembly Chemistry for Organic Functional Molecules, Shanghai Institute of Organic Chemistry, Chinese Academy of Sciences, 345 Lingling Road, Shanghai 200032, P. R. China. E-mail: sunjing@sioc.ac.cn; qiangfang@sioc.ac.cn; Fax: +86-22-54925519; Tel: +86-21-54925337

${ }^{b}$ State Key Laboratory of Polymer Materials Engineering, Sichuan University, Chengdu 610065, P. R. China

$\dagger$ Electronic supplementary information (ESI) available. See DOI: 10.1039/c5ra01515d behavior ${ }^{15-17}$ and excellent triplet emission properties. ${ }^{18}$ These good properties imply that PMPs may have the potential applications in the fields of biology $y^{15-17}$ and information..$^{16,17}$

However, the above-mentioned PMPs usually have low molecular weight..$^{20,23-25}$ The low molecular weight will generally lead to the low transition temperatures and the mechanical properties, which restricts the useful commercial applications of the polymer materials. Thus, great efforts have been made to improve the molecular weight and expand application of PMPs. For example, A. D. Schlüter and coworkers ${ }^{14}$ investigated the copolymerization of $p$-phenylene and $m$-phenylene monomers under Suzuki coupling condition. J. Sakamoto group ${ }^{19}$ developed a new route, in which an $\mathrm{AB}$ monomer containing both boric ester and bromo group was employed. After treated the $\mathrm{AB}$ monomer under the improved Suzuki coupling condition, PMPs with high molecular weight were obtained. Nevertheless, in some cases, the Suzuki coupling gave the polymers consisting of cyclic oligomers and open-chain fractions. ${ }^{19}$ Undoubtedly, further investigation on the synthesis and application of high molecular weight PMPs is still desirable.

To the best of our knowledge, a simple and efficient strategy to improve molecular weight of the polymers is postpolymerization. ${ }^{26-28}$ For instance, introducing the thermally crosslinkable groups into the backbone of PMPs could greatly amplify the molecular weight of the polymer during postpolymerization at high temperature. It is noted that propargyl ether is one of the frequently-used thermally crosslinkable groups and the formed cross-linked networks have high 
thermostability and good mechanical properties. ${ }^{29,30}$ The characteristic of propargyl group inspires us to introduce this group into the backbone of PMPs. We hence design and synthesize a new PMPs consisting of propargyl ether as the side chains. The new polymer exhibits good film-forming ability and solubility. After heated at high temperature, PE-PMP film transforms to a cross-linked network, which shows low coefficient of thermal expansion (CTE) ranging from 30 to $300{ }^{\circ} \mathrm{C}$. In particular, the cured PE-PMP shows high glass transition temperature $\left(T_{\mathrm{g}}\right)$ and high modulus. These data are superior to those of the commercial epoxy and novolac resins and polyimides. ${ }^{31}$ Moreover, the cured PE-PMP possesses low dielectric constant in a range of frequencies from $2 \mathrm{MHz}$ to $30 \mathrm{MHz}$.

It is noted that the high-performance polymers should possess the characteristics, including high mechanical stiffness, low dielectric constant and coefficient of thermal expansion (CTE) and easy processability. ${ }^{32}$ The good properties that the cured PE-PMP showed suggest that PE-PMP could be a useful precursor used as insulative coatings for electrical wires and electronic packaging, as well as the based matrix for preparation of advanced printed circuit boards composites.

\section{Results and discussion}

\section{Synthesis and characterization}

Scheme 1 depicts a route for the preparation of propargyl etherfunctionalized PMP (PE-PMP). As shown in Scheme 1, monomer 1 was prepared in a high yield by a reaction between 4-methoxyphenol and 1,3,5-trichlorobenzene in the presence of a strong inorganic base at high temperature. The polymerization of monomer 1 was carried out by using a nickel-mediated homo-coupling reaction ${ }^{33}$ in DMAc. The obtained polymer 2 showed the number-average molecular weight $\left(M_{\mathrm{n}}\right)$ and polydispersity index (PDI) of 3500 and 1.64, respectively. Such a $M_{\mathrm{n}}$ is consistent with the result previously reported. ${ }^{18,23,25}$ The polymer with such a molecular weight has good solubility in organic solvents for the further processing. By a simple demethylation reaction, polymer 2 was transformed to polymer 3 . Finally, polymer PE-PMP was successfully synthesized with a $M_{\mathrm{n}}$ and PDI of 5050 and 1.50, respectively. In comparison with the starting polymer 2, the target polymer PE-PMP showed more repeating units (23 for polymer PE-PMP and 18 for polymer 2). Such difference was attributed to the multi-step precipitation routes, in which the low molecular fractions were removed.

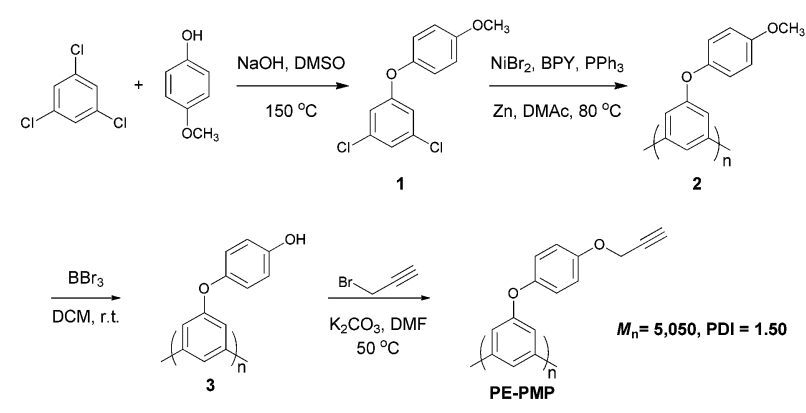

Scheme 1 Synthesis of PE-PMP.
PE-PMP had good solubility in common organic solvents such as $\mathrm{CHCl}_{3}$, THF, toluene, DMF, acetone, hexane and cyclohexanone. Casting or spin-coating from a solution of PE-PMP in toluene gave flat and transparent films (see ESI, Fig. S1†).

The chemical structure of PE-PMP was confirmed by ${ }^{1} \mathrm{H}$ NMR, ${ }^{13} \mathrm{C}$ NMR, FT-IR spectra and elemental analysis (EA). The detailed data are listed in the experimental section. Fig. 1 exemplifies the ${ }^{1} \mathrm{H}$ and ${ }^{13} \mathrm{C}$ NMR of PE-PMP. As can be seen from Fig. 1, all data are consistent with the proposed structure.

\section{Postpolymerization of PE-PMP}

At high temperature, aryl propargyl ether has a tendency to form chromene through [3,3]-sigmatropic rearrangement. ${ }^{34}$ For PEPMP, the thermal crosslinking of propargyl ether units makes the polymer convert to cross-linked network. Such a crosslinking reaction ${ }^{\mathbf{2 9 , 3 0 , 3 4}}$ (or postpolymerization) is depicted in Scheme 2, and it is monitored by DSC traces (Fig. 2). As shown in Fig. 2, PE-PMP softens at $73{ }^{\circ} \mathrm{C}$ and starts the cross-linking reaction at about $212{ }^{\circ} \mathrm{C}$. The polymer gives a maximum exothermic peak at $268^{\circ} \mathrm{C}$, similar to the curing behaviors of the polymers containing propargyl ether units. ${ }^{29,30}$ The curing degree of PE-PMP was also examined by DSC. Fig. 2 exhibits the DSC trace (red line) of the postpolymerized PE-PMP, which have been cured at $320^{\circ} \mathrm{C}$ for $3 \mathrm{~h}$. Obviously, the straight DSC trace implies that PE-PMP has been fully converted to the crosslinked network. In other words, the postpolymerization of PE-PMP can be achieved at $320^{\circ} \mathrm{C}$ for $3 \mathrm{~h}$.

The curing degree of PE-PMP was also evaluated by FT-IR spectra. Fig. 3 depicts a comparison of the FT-IR spectra between PE-PMP and cured PE-PMP. After postpolymerization, the characteristic absorption peak of alkyne group both in $3292 \mathrm{~cm}^{-1}$ (C-H stretching vibration) and $2123 \mathrm{~cm}^{-1}(\mathrm{C} \equiv \mathrm{C}$ stretching vibration) completely disappeared, indicating the completion of curing process.

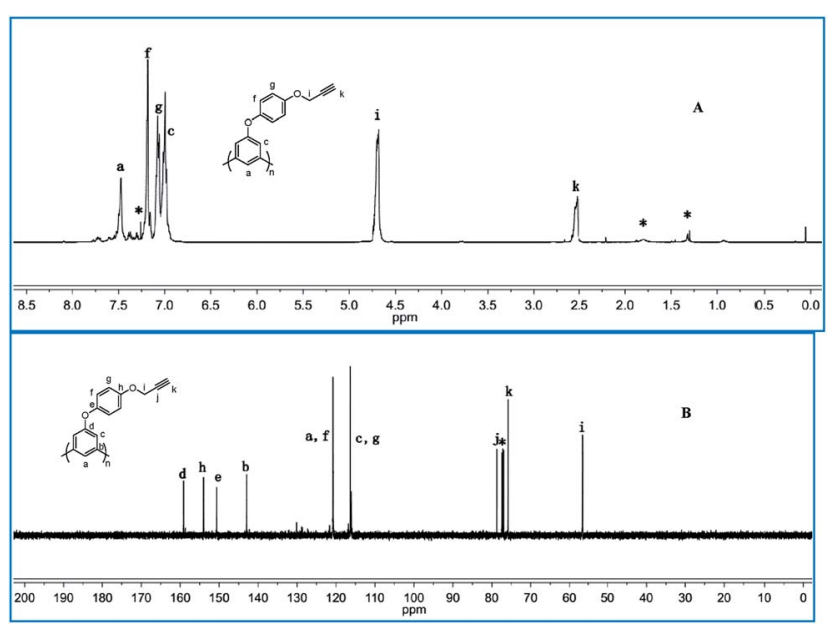

Fig. $1{ }^{1} \mathrm{H}$ NMR (A, $\left.500 \mathrm{MHz}, \mathrm{CDCl}_{3}\right)$ and ${ }^{13} \mathrm{C} \mathrm{NMR}$ spectra $(\mathrm{B}, 126 \mathrm{MHz}$, $\mathrm{CDCl}_{3}$ ) of PE-PMP. The asterisks indicate $\mathrm{CHCl}_{3}$ and the impurity in $\mathrm{CDCl}_{3}$, respectively. 

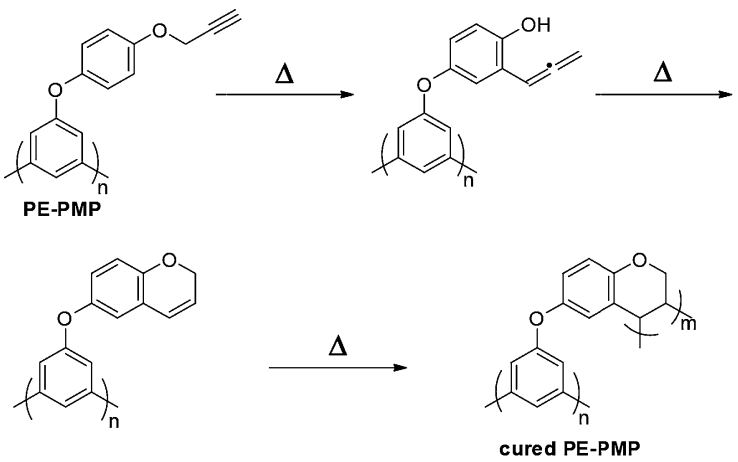

Scheme 2 Postpolymerization reaction of PE-PMP.

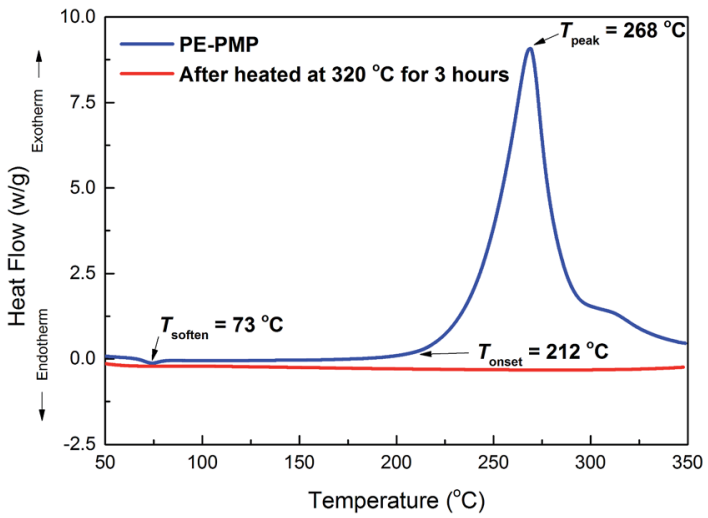

Fig. 2 DSC trace of PE-PMP at a heating rate of $10{ }^{\circ} \mathrm{C} \mathrm{min}^{-1}$ in $\mathrm{N}_{2}$.

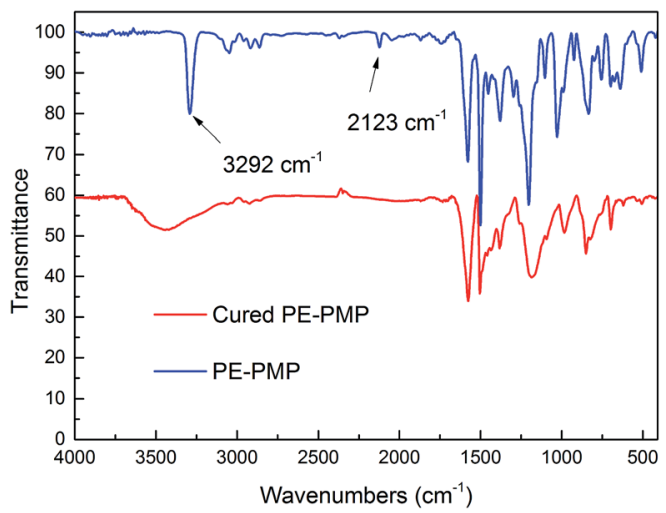

Fig. 3 FT-IR spectra of PE-PMP and cured PE-PMP.

\section{Thermostability of the cured PE-PMP}

Thermostability of cured PE-PMP was evaluated by TGA in nitrogen and air atmosphere, and the results are depicted in Fig. 4. As shown in Fig. 4, cured PE-PMP exhibits 5 wt $\%$ loss in nitrogen and air at $471{ }^{\circ} \mathrm{C}$ and $451{ }^{\circ} \mathrm{C}$, respectively. It is noteworthy that there is only $20^{\circ} \mathrm{C}$ decreased from nitrogen to air in temperature of the $5 \mathrm{wt} \%$ loss, which means that the material shows high thermostability in air and could be applied in fireresistant field. Moreover, the cured polymer shows a char

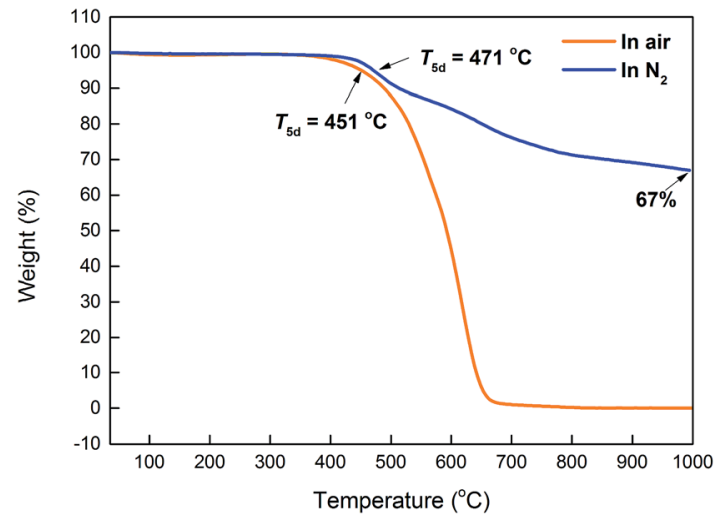

Fig. 4 TGA curves of cured PE-PMP at a heating rate of $10^{\circ} \mathrm{C} \mathrm{min}^{-1}$.

yield of $67 \%$ in nitrogen at $1000{ }^{\circ} \mathrm{C}$. These data indicate that cured PE-PMP has high thermostability.

\section{Mechanical properties of cured PE-PMP}

High glass-transition temperature $\left(T_{\mathrm{g}}\right)$ and low coefficient of thermal expansion (CTE) are the important characteristics of high-performance engineering materials. For our newly designed material PE-PMP, the mechanical properties were measured by dynamic mechanical analysis (DMA) and thermo mechanical analysis (TMA).

Fig. 5 shows the DMA results of cured PE-PMP. For comparison, two types of common commercial epoxy resins (DER331 and DEN431) were chosen, which have been widely utilized in electric and microelectronic industry. As can be seen from Fig. 5, cured PE-PMP possesses high storage modulus about $7.5 \mathrm{GPa}$ at room temperature and slowly decreases to $4.0 \mathrm{GPa}$ with the temperature increasing to $300{ }^{\circ} \mathrm{C}$. Meanwhile, cured PE-PMP shows no obvious glass transition behavior even at the temperature of $300{ }^{\circ} \mathrm{C}$. In contrast, DDS $\left(4,4^{\prime}\right.$-diaminodiphenyl sulfone) cured DER331 and DEN431 show low storage modulus (about 2.0 GPa) at room temperature and somewhat low glass transition temperature $\left(215{ }^{\circ} \mathrm{C}\right.$ for DER331 and $225^{\circ} \mathrm{C}$ for DEN431).

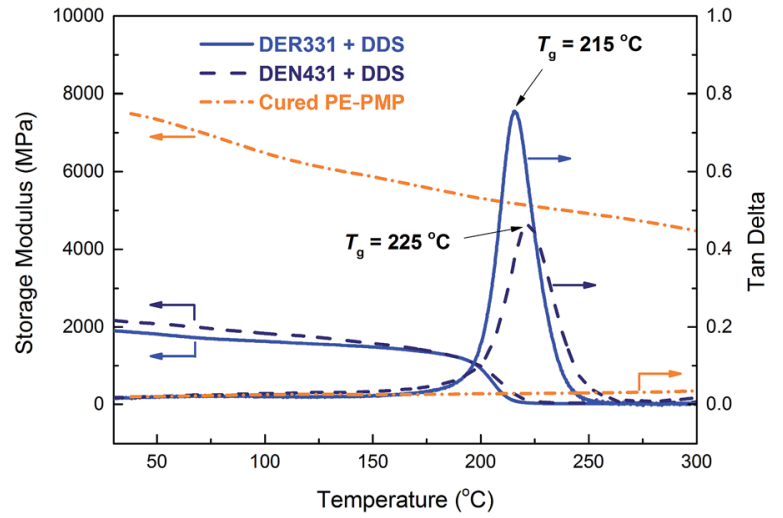

Fig. 5 DMA curves of cured PE-PMP, DER331 and DEN431. The mass ratio of DER331 (or DEN431) to DDS in curing is $3.16: 1$. 
It is noted that coefficient of thermal expansion (CTE) is an important factor that describes how the size of an object changes with a change of temperature. For the isotropic materials, linear CTE is to identify the ability of thermal expansion of a material. For cured PE-PMP, X-ray diffraction (XRD) (see ESI, Fig. S2 $\dagger$ ) shows that the polymer is amorphous, suggesting that such material is isotropic. Fig. 6 exhibits the relative length changes $(\mathrm{d} L / L)$ of a cured PE-PMP matrix (having a size of $5 \mathrm{~mm}$ $\times 3 \mathrm{~mm} \times 2 \mathrm{~mm}$ ) with the temperature. Here, the CTE values are equal to the slope according to the equation $\mathrm{d} L / L=\alpha_{\mathrm{L}} \mathrm{d} T$, where $\alpha_{\mathrm{L}}$ represents linear CTE of a material and $\mathrm{d} T$ is the differential coefficient of the temperature, respectively. As shown in Fig. 6, cured PE-PMP shows an average linear CTE of $30.6 \mathrm{ppm}{ }^{\circ} \mathrm{C}^{-1}$ in a range of temperatures from 30 to $300{ }^{\circ} \mathrm{C}$. This CTE is comparable to that of metal plumbum and better than those of the commercial epoxy resins. It is noteworthy that an interesting phenomenon occurs when the temperature rises above $150{ }^{\circ} \mathrm{C}$, the CTE of cured PE-PMP decreases to $21.3 \mathrm{ppm}$ ${ }^{\circ} \mathrm{C}^{-1}$. Moreover, cured PE-PMP shows a high $T_{\mathrm{g}}\left(\right.$ near $\left.330{ }^{\circ} \mathrm{C}\right)$, which is much higher than that of the commercial epoxy resins. From an application point of view, the materials with low CTE and high $T_{\mathrm{g}}$ are very desirable for their application in electrical and microelectronic industry.

The mechanical properties of cured PE-PMP film were also measured by nanoindentation test. The results show that the film has an average hardness of $1.22 \mathrm{GPa}$, a Young's modulus of 9.44 GPa and a bonding strength to the silicon wafer of $783 \mathrm{MPa}$, respectively. The obtained data indicated that the polymer have good mechanical properties.

\section{Dielectric properties of cured PE-PMP}

The dielectric properties of cured PE-PMP were conducted by the capacitance method. ${ }^{35}$ The device was prepared by precuring of PE-PMP at $150{ }^{\circ} \mathrm{C}$ in vacuum followed by postpolymerization to obtain a dark brown product. The results are illustrated in Fig. 7. As can be seen from Fig. 7, cured PE-PMP exhibits dielectric constants $(k)$ values in a range of 2.84 to 3.02 along with dissipation factors $(\tan \delta$ ) below 0.014 , ranging the frequencies from $2 \mathrm{MHz}$ to $30 \mathrm{MHz}$. Such low $k$ and $\tan \delta$

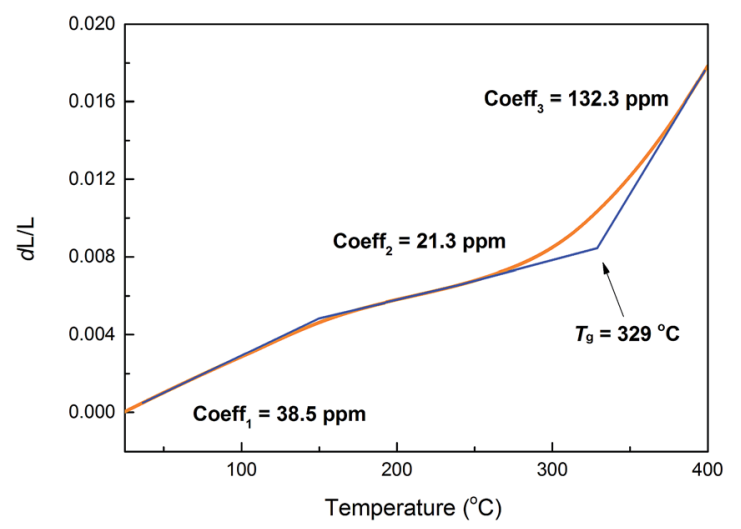

Fig. 6 Relative length change $(d L / L)$ versus temperature $(T)$ of cured PE-PMP.

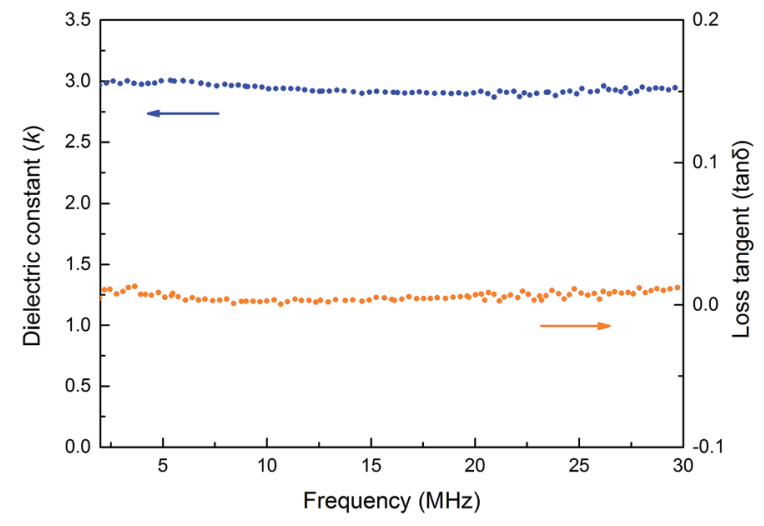

Fig. 7 Dielectric constants $(k)$ and dissipation factors $(\tan \delta)$ of cured PE-PMP.

values are also desirable in electrical and microelectronic industry.

\section{Conclusions}

A new poly $(m$-phenylene) functionalized with propargyl ether has been successfully synthesized. This polymer shows good solubility in the common organic solvents and good filmforming ability. After postpolymerization at high temperature, the polymer converts into a cross-linked network, which shows high thermostability, modulus and $T_{\mathrm{g}}$, as well as low dielectric constant and good mechanical properties. Those data imply that the new polymer can be used as a matrix resin for the preparation of high performance composite applied in microelectronic and aerospace industry.

\section{Experimental section}

\section{Materials and instrumentation}

All starting chemicals were purchased from Aldrich and used without further purification unless otherwise stated. The solvents utilized in this contribution were distilled from calcium hydride and stored under an argon atmosphere. Two commercial epoxy resins, DER331 (an bisphenol A type epoxy resin with epoxy equivalent weight of 182-192 $\mathrm{g} \mathrm{eq.}^{-1}$ ) and DEN431 (an novolac type epoxy resin with epoxy equivalent weight of $172-179 \mathrm{~g}$ eq. $^{-1}$ ) were purchased from The Dow Chemical Company and used as received.

${ }^{1} \mathrm{H}$ NMR and ${ }^{13} \mathrm{C}$ NMR spectra were obtained on a Bruker AV-400 or Agilent 500/54/ASP instrument. FT-IR spectra were recorded on a Thermo Scientific Nicolet spectrometer with $\mathrm{KBr}$ pellets. Differential Scanning Calorimetry (DSC) was determined with TA Instrument DSC Q200 at a heating rate of $10{ }^{\circ} \mathrm{C}$ $\min ^{-1}$ under nitrogen flow. Thermogravimetric analysis (TGA) was performed on a TG 209F1 apparatus with a heating rate of $10{ }^{\circ} \mathrm{C} \mathrm{min}^{-1}$ in nitrogen or air atmosphere. Molecular weights were measured by using a Waters Breeze2a 200 GPC instrument with polystyrene as standards and tetrahydrofuran (THF) as the eluent at $35{ }^{\circ} \mathrm{C}$. The dielectric constants $(k)$ of the cured samples were measured in the range of frequencies from $2 \mathrm{MHz}$ to 
$30 \mathrm{MHz}$ at room temperature by a 4294A Precision Impedance Analyzer (Agilent). The surface toughness of the cured polymer film was measured by atom force microscopy (AFM) (Shimadzu SPM-9500J3). A TI 950 TriboIndenter (Hysitron) was used to measure the mechanical properties of films including hardness, Young's modulus and bonding strength. Dynamic mechanical analysis (DMA) and thermo-mechanical analysis (TMA) were recorded on the Mettler Toledo DMA/SDTA861e and TMA/SDTS841e instruments, respectively with a heating rate of $3{ }^{\circ} \mathrm{C} \min ^{-1}$ in air.

\section{Synthesis}

Synthesis of 1,3-dichloro-5-(4-methoxyphenoxy)benzene (monomer 1). $\mathrm{NaOH}$ pellets $(7.1 \mathrm{~g}, 177 \mathrm{mmol})$ was added to a stirring solution of 4-methoxyphenol (20.00 g, $161 \mathrm{mmol})$ and 1,3,5-trichlorobenzene (43.85 g, $242 \mathrm{mmol})$ in DMSO $(200 \mathrm{~mL})$ at room temperature. The resulting mixture was heated to $150{ }^{\circ} \mathrm{C}$ and stirred at the temperature for about $5 \mathrm{~h}$. After the mixture was cooled to room temperature, water $(300 \mathrm{~mL})$ was added. The obtained mixture was extracted with ethyl acetate $(3 \times 300 \mathrm{~mL})$. The combined organic phase was washed with brine $(400 \times 3 \mathrm{~mL})$ and dried over anhydrous $\mathrm{MgSO}_{4}$. After filtration and removal of the solvent under vacuum, the residue was purified by a flash column chromatography on $\mathrm{SiO}_{2}$ with hexane as the eluent. Monomer 1 was obtained as a white solid in a yield of $91.2 \%(35.39 \mathrm{~g})$ and with a purity of $99.4 \%$ (HPLC). ${ }^{1} \mathrm{H}$ NMR (500 MHz, $\left.\mathrm{CDCl}_{3}\right): \delta 7.04(\mathrm{dd}, J=3.7,2.0 \mathrm{~Hz}, 1 \mathrm{H})$, 7.03-7.00 (m, 2H), 6.97-6.92 (m, 2H), $6.86(\mathrm{~d}, J=1.8 \mathrm{~Hz}, 2 \mathrm{H})$, $3.83(\mathrm{~s}, 3 \mathrm{H}) .{ }^{13} \mathrm{C} \mathrm{NMR}\left(126 \mathrm{MHz}, \mathrm{CDCl}_{3}\right): \delta 160.08,156.83$, $148.39,135.55,122.39,121.51,115.82,115.17,55.54$. HRMS $(\mathrm{m} / \mathrm{z}):[\mathrm{M}]^{+}$calcd for $\mathrm{C}_{13} \mathrm{H}_{10} \mathrm{Cl}_{2} \mathrm{O}_{2}, 268.0058$. Found 268.0057 .

Synthesis of polymer (2). To a flame dried Schlenk tube charged with $\mathrm{NiBr}_{2}(2.18 \mathrm{~g}, 10 \mathrm{mmol}), 2,2^{\prime}$-bipyridine (BPY, $1.56 \mathrm{~g}, 10 \mathrm{mmol}), \mathrm{PPh}_{3}(13.11 \mathrm{~g}, 50 \mathrm{mmol})$ and zinc dust (9.75 g, $150 \mathrm{mmol})$, dry $N, N$-dimethylamide acetate (DMAc) $(60 \mathrm{~mL})$ was added under an atmosphere of argon. The mixture was degassed and stirred at room temperature for $1 \mathrm{~h}$. When the solution changed into red brown, monomer 1 (13.45 g, $50 \mathrm{mmol}$ ) was added. The mixture was heated to $80^{\circ} \mathrm{C}$ and kept at the temperature for 3 days. The resulting black mixture was diluted with DMAc $(50 \mathrm{~mL})$, filtered through celite, and then poured into $1000 \mathrm{~mL}$ of methanol containing concentrated $\mathrm{HCl}$ $(50 \mathrm{~mL})$. The obtained precipitate was dissolved in $\mathrm{CHCl}_{3}$ and reprecipitated in methanol. After filtration, washing with methanol, and drying under vacuum at $80^{\circ} \mathrm{C}$ for $10 \mathrm{~h}$, polymer 2 was obtained (9.8 g, yield $\left.100 \%) .{ }^{1} \mathrm{H} \mathrm{NMR} \mathrm{(400} \mathrm{MHz}, \mathrm{CDCl}_{3}\right): \delta$ 7.55-7.30 (m, 2H), 7.21-7.12 (m, 1H), 7.10-6.81 (m, 4H), 3.91-3.72 (m, 3H). ${ }^{13} \mathrm{C} \mathrm{NMR}\left(126 \mathrm{MHz}, \mathrm{CDCl}_{3}\right): \delta 159.44,156.22$, 149.78, 143.01, 121.00, 120.61, 115.79, 115.12, 55.73. Anal. calcd for $\left(\mathrm{C}_{13} \mathrm{H}_{10} \mathrm{O}_{2}\right)_{n}$ : C, 78.77; H, 5.09. Found: C, 77.53; H, 5.09.

Synthesis of polymer (3). To a stirring solution of polymer 2 (9.82 g) in $\mathrm{CH}_{2} \mathrm{Cl}_{2}(150 \mathrm{~mL}), \mathrm{BBr}_{3}\left(2.4 \mathrm{M}\right.$ in $\left.\mathrm{CH}_{2} \mathrm{Cl}_{2}, 50 \mathrm{~mL}\right)$ was added at $0{ }^{\circ} \mathrm{C}$. The mixture was warmed to room temperature and stirred at the temperature overnight. The resulting mixture was slowly poured into ice-cooled methanol $(800 \mathrm{~mL})$ and stirred for $30 \mathrm{~min}$. After removal of the solvent under vacuum, the residue was precipitated in deionized water. The obtained precipitate was re-dissolved in acetone and reprecipitated in deionized water. Polymer 3 was thus obtained in a yield of $84 \%$ $(7.3 \mathrm{~g})$ after filtration, washing with deionized water, and drying under vacuum at $80{ }^{\circ} \mathrm{C}$ for $24 \mathrm{~h} .{ }^{1} \mathrm{H}$ NMR (500 MHz, acetone- $\left.\mathrm{d}_{6}\right)$ : $\delta$ 7.80-7.57 (m, 1H), 7.42-7.08 (m, 2H), 7.03-6.83 (m, 4H). ${ }^{13} \mathrm{C}$ NMR (126 MHz, acetone- $\mathrm{d}_{6}$ ): $\delta$ 160.84, 154.88, 149.56, 143.76, 122.16, 122.06, 117.29, 117.21.

Synthesis of PE-PMP. To a stirring solution of polymer 3 $(6.84 \mathrm{~g})$ in DMF $(70 \mathrm{~mL})$ was added $\mathrm{K}_{2} \mathrm{CO}_{3}(12.83 \mathrm{~g}, 93 \mathrm{mmol})$ and 3-bromopropyne $(11.02 \mathrm{~g}, 8.1 \mathrm{~mL}, 93 \mathrm{mmol})$ at room temperature. The resulting mixture was stirred constantly at room temperature for $2 \mathrm{~h}$ and at $50{ }^{\circ} \mathrm{C}$ for $10 \mathrm{~h}$, respectively. After cooled to room temperature, the mixture was quenched with $\mathrm{H}_{2} \mathrm{O}(100 \mathrm{~mL})$ and extracted with $\mathrm{CHCl}_{3}(3 \times 100 \mathrm{~mL})$. The combined organic phase was washed with brine $(200 \mathrm{~mL})$ and dried over anhydrous $\mathrm{MgSO}_{4}$. After filtration and removal of the solvent under vacuum, the residue was precipitated in methanol. The obtained precipitate was re-dissolved in $\mathrm{CHCl}_{3}$ and reprecipitated in methanol. PE-PMP was obtained by filtration, washing with methanol and drying under vacuum at $80{ }^{\circ} \mathrm{C}$ for 10 h. Yield: $7.7 \mathrm{~g}, 93 \%$. ${ }^{1} \mathrm{H}$ NMR (500 $\mathrm{MHz}, \mathrm{CDCl}_{3}$ ): $\delta 7.54-7.43$ (m, 1H), 7.24-7.14 (m, 2H), 7.12-6.92 (m, 4H), 4.75-4.65 (m, 2H), 2.59-2.48 (m, 1H). ${ }^{13} \mathrm{C}$ NMR (126 MHz, $\left.\mathrm{CDCl}_{3}\right): \delta 159.10$, 154.00, 150.59, 142.94, 120.75, 116.35, 116.26, 116.04, 78.68, 75.82, 56.39. Anal. calcd for $\left(\mathrm{C}_{15} \mathrm{H}_{10} \mathrm{O}_{2}\right)_{n}$ : C, 81.07; H, 4.54. Found: C, 80.28, H, 4.55 .

Cured PE-PMP sample preparation. PE-PMP (3.5 g) was placed in a flat-bottomed glass tube $(\phi=8 \mathrm{~mm}$, and highness of $10 \mathrm{~cm}$ ) filled with argon. The tube was heated to $150{ }^{\circ} \mathrm{C}$ and kept at the temperature for $5 \mathrm{~h}$ so that a transparent melting liquid was obtained. The temperature was then elevated and kept at $200{ }^{\circ} \mathrm{C}$ for $1 \mathrm{~h}, 220^{\circ} \mathrm{C}$ for $1 \mathrm{~h}, 250^{\circ} \mathrm{C}$ for $2 \mathrm{~h}, 270{ }^{\circ} \mathrm{C}$ for $2 \mathrm{~h}$, and $320^{\circ} \mathrm{C}$ for $3 \mathrm{~h}$, respectively. Thus, a completely cured sample was obtained.

\section{Acknowledgements}

Financial supports from the Natural Science Foundation of China (NSFC, no. 21374131), the Shanghai Natural Science Foundation (no. 15ZR1449200) and the Opening Project of State key laboratory of Polymer Materials Engineering (Sichuan University, Grant no. sklpme2014-4-22) are gratefully acknowledged.

\section{References}

1 P. Kovacic and M. B. Jones, Chem. Rev., 1987, 87, 357-379.

2 J. M. Tour, Adv. Mater., 1994, 6, 190-198.

3 A. C. Grimsdale, K. L. Chan, R. E. Martin, P. G. Jokisz and A. B. Holmes, Chem. Rev., 2009, 109, 897-1091.

4 L.-H. Xie, C.-R. Yin, W.-Y. Lai, Q.-L. Fan and W. Huang, Prog. Polym. Sci., 2012, 37, 1192-1264.

5 L. Chen, Y. Chen, K. Yao, W. Zhou, F. Li, L. Chen, R. Hu and B. Z. Tang, Macromolecules, 2009, 42, 5053-5061.

6 P. Baum, W. H. Meyer and G. Wegner, Polymer, 2000, 41, 965-973. 
7 Y. Takeoka, K. Umezawa, T. Oshima, M. Yoshida, M. Yoshizawa-Fujita and M. Rikukawa, Polym. Chem., 2014, 5, 4132-4140.

8 M. R. Talipov, A. Boddeda, Q. K. Timerghazin and R. Rathore, J. Phys. Chem. C, 2014, 118, 21400-21408.

9 L. Tao, J. Ju, F. Niu, T. Wang and Q. Wang, Polymer, 2013, 54, 5358-5362.

10 C. Schwarz, H. Bässler, I. Bauer, J. M. Koenen, E. Preis, U. Scherf and A. Köhler, Adv. Mater., 2012, 24, 922-925.

11 S. Schmücker and D. Kuckling, Macromol. Chem. Phys., 2012, 213, 1725-1734.

12 Y. Y. Durmaz, E. L. Sahkulubey, Y. Yagci, E. Martinelli and G. Galli, J. Polym. Sci., Part A: Polym. Chem., 2012, 50, 4911-4919.

13 P. Rattanatraicharoen, Y. Tanaka, K. Shintaku, T. Kawaguchi, K. Yamabuki, T. Oishi and K. Onimura, $J$. Polym. Sci., Part A: Polym. Chem., 2013, 51, 1315-1322.

14 R. Kandre, K. Feldman, H. E. Meijer, P. Smith and A. D. Schlüter, Angew. Chem., Int. Ed., 2007, 46, 4956-4959.

15 H. Katagiri, T. Miyagawa, Y. Furusho and E. Yashima, Angew. Chem., Int. Ed., 2006, 45, 1741-1744.

16 T. Ben, H. Goto, K. Miwa, H. Goto, K. Morino, Y. Furusho and E. Yashima, Macromolecules, 2008, 41, 4506-4509.

17 T. Ben, Y. Furusho, H. Goto, K. Miwa and E. Yashima, Org. Biomol. Chem., 2009, 7, 2509-2512.

18 J. Liu and Q. Pei, Macromolecules, 2010, 43, 9608-9612.

19 B. Hohl, L. Bertschi, X. Zhang, A. D. Schlüter and J. Sakamoto, Macromolecules, 2012, 45, 5418-5426.

20 J. Tong, S. Diao, K. Jin, C. Yuan, J. Wang, J. Sun and Q. Fang, Polymer, 2014, 55, 3628-3633.
21 X. Zhang, L. Sheng, T. Higashihara and M. Ueda, Polym. Chem., 2013, 4, 1235-1242.

22 S. Y. Hong, D. Y. Kim, C. Y. Kim and R. Hoffmann, Macromolecules, 2001, 34, 6474-6481.

23 L. J. Mathias and G. L. Tullos, Polymer, 1996, 37, 3771-3774.

24 J. L. Reddinger and J. R. Reynolds, Macromolecules, 1997, 30, 479-481.

25 T. Yamamoto, M. Abe, B. Wu, B. K. Choi, Y. Harada, Y. Takahashi, K. Kawata, S. Sasaki and K. Kubota, Macromolecules, 2007, 40, 5504-5512.

26 M. A. Gauthier, M. I. Gibson and H. A. Klok, Angew. Chem., Int. Ed., 2009, 48, 48-58.

27 J. Romulus, J. T. Henssler and M. Weck, Macromolecules, 2014, 47, 5437-5449.

28 C. Yuan, J. Wang, K. Jin, S. Diao, J. Sun, J. Tong and Q. Fang, Macromolecules, 2014, 47, 6311-6315.

29 T. Agag and T. Takeichi, Macromolecules, 2001, 34, 72577263.

30 K. D. Demir, B. Kiskan and Y. Yagci, Macromolecules, 2011, 44, 1801-1807.

31 D.-J. Liaw, K.-L. Wang, Y.-C. Huang, K.-R. Lee, J.-Y. Lai and C.-S. Ha, Prog. Polym. Sci., 2012, 37, 907-974.

32 W. R. Shiang and E. P. Woo, J. Polym. Sci., Part A: Polym. Chem., 1993, 31, 2081-2091.

33 V. Percec, J. Y. Bae, M. Zhao and D. H. Hil, Macromolecules, 1995, 28, 6726-6734.

34 J. Zsindely and H. Schmidt, Helv. Chim. Acta, 1968, 51, 15101514.

35 C. Yuan, K. Jin, K. Li, S. Diao, J. Tong and Q. Fang, Adv. Mater., 2013, 25, 4875-4878. 